TRABAJOS DE PREHISTORIA

66, N. ${ }^{\circ}$ 2, julio-diciembre 2009, pp. 7-23, ISSN: 0082-5638

doi: $10.3989 /$ tp.2009.09027

\title{
Ámbitos sociales compartidos: convergencia evolutiva en la Prehistoria y la práctica contemporánea
}

\author{
Shared Social Fields: evolutionary convergence in prehistory and contemporary practice
}

Philip L. Kohl (*)

\section{RESUMEN}

En este artículo distingo entre perspectivas evolucionistas e históricas sobre el pasado, adoptando el concepto de "ámbitos sociales" para defender una interpretación macrohistórica del registro arqueológico. La unidad de análisis no es una cultura o civilización arqueológica sino los grupos sociales implicados de manera inextricable con otros grupos en interconexiones reticulares en las que las tecnologías son difundidas y modificadas por otros grupos atrapados en esos mismos procesos. Tales interconexiones pueden ser trazadas mejor arqueológicamente examinando la expansión de las tecnologías y las prácticas subsistenciales. Otras perspectivas macrohistóricas sobre el pasado, como el análisis de los sistemas mundiales, a menudo exigen demasiado del registro arqueológico y son empleadas de manera anacrónica. La Prehistoria documenta la siempre creciente participación de los grupos en ámbitos sociales que, finalmente, convergen. Concluyo haciendo hincapié en la necesidad de una perspectiva acerca del pasado que resalte su naturaleza compartida en la que todos los pueblos han contribuido a las interacciones con sus vecinos y se han beneficiado de ellas.

\begin{abstract}
In this article, I distinguish between evolutionary and historical perspectives on the past, adopting the concept of "social fields" to argue for a macrohistorical interpretation of the archaeological record. The unit of analysis is not an archaeological culture or civilization but social groups inextricably involved with other groups in weblike interconnections in which technologies are diffused and modified by other groups caught up in these same processes. Such interconnections can best be traced archaeologically by examining the spread of technologies and subsistence practices. Other macrohistorical perspec-
\end{abstract}

(*) Wellesley College. Wellesley, MA 02481. USA. Correo electrónico: pkohl@wellesley.edu.

Recibido: 6-V-2009; aceptado: 11-IX-2009. tives on the past, such as world systems analysis, often demand too much of the archaeological record and are used anachronistically. Prehistory documents the ever-increasing participation of groups in social fields that ultimately converge. I conclude by emphasizing the need for a perspective on the past that emphasizes its shared nature in which all peoples have contributed and benefited from interactions with their neighbours.

Palabras clave: Ámbitos sociales; Historia; Evolución; Difusión; Análisis de los sistemas mundiales; Edad del Bronce Eurasia.

Key words: Social fields; History; Evolution; Diffusion; World systems analysis; Bronze Age Eurasia.

\section{INTRODUCCIÓN: VOLVIENDO A DEFINIR UN CONCEPTO CENTRAL DE LA ANTROPOLOGÍA (1)}

Dos años después de publicar Europa y las gentes sin Historia, Eric Wolf (1984) escribió un breve artículo destinado a los arqueólogos en American Antiquity titulado "La cultura: ¿panacea o problema?". Wolf sugería que el concepto de cultura, que había sido recientemente defendido por Kent Flannery (1982) en su celebrada fábula del palustre de oro de la empresa Marshalltown (2) se tenía que volver a conceptualizar. No

(1) (C) de la American Anthropological Association. Traducción de M. ${ }^{a}$ Isabel Martinez Navarrete (Grupo de investigación Prehistoria social y económica, Instituto de Historia, CCHS-CSIC, Madrid), revisada por el autor.

(2) Wolf se refiere explícitamente a la parábola de Flannery en la página inicial de este artículo, criticando al Veterano de Flannery por su enérgica defensa de la cultura como un todo integrado que permitía a los arqueólogos comprender los nexos entre todos los artefactos excavados en un sitio. El Veterano, que estaba a punto de perder su trabajo en el cuento de Flannery, 
era la panacea pero, si acaso, por lo menos proporcionaba "un punto de partida a la investigación" para buscar interconexiones más amplias entre culturas:

“... En la mayoría de los casos las entidades estudiadas por los antropólogos (culturas) deben su desarrollo a procesos que se originan fuera de ellas y que van más allá de ellas, su cristalización se debe a esos procesos, en los que participan y que les afectan a su vez. Designaciones tales como Ojibwa, Iroqués, Chipeweyan, Assiniboin, Crow, Pies Negros, Zulu, Tswana se configuraron en un campo social y cultural más amplio que incluyó viajeros, militares, mercaderes de esclavos, primeros comerciantes, jesuitas, agentes de la 'Bahía de Hudson' y otros" (Wolf 1984: 395-396).

De manera similar, aunque de forma más abstracta, Wolf (1982: 6) comenzó su monumental Europa y las gentes sin Historia, argumentando contra la creación de cualesquiera agregados sociales abstractos -estados-nación, sociedades o culturas- como objetos aislados, delimitados, internamente homogéneos y externamente distintivos. Citando su párrafo inicial (3):

"La tesis central de esta obra es que el mundo de la humanidad constituye un total de procesos múltiples interconectados y que los empeños por descomponer en sus partes a esta totalida que luego no pueden rearmarla, falsean la realidad. Conceptos tales como 'nación', 'sociedad' y 'cultura' designan porciones y pueden llevarnos a convertir nombres en cosas. Sólo comprendiendo estos nombres como hatos de relaciones y colocándolos de nuevo en el terreno del que fueron abstraídos, podemos esperar evitar inferencias engañosas y acrecentar nuestra comprensión" (Wolf 1982: 3).

Wolf estaba interesado en escribir una historia a gran escala que abarcara esencialmente el último medio milenio y empleó de manera creativa el concepto marxista de modo de producción para ordenar sus datos. Sin embargo insistió en que

merecía ser despedido por su concepción anticuada de la cultura entendida a la manera de la estadística como un todo integrado de prácticas compartidas, costumbres y creencias que los datos arqueológicos materializan.

Nota de la traductora: la empresa Marshalltown está especializada en herramientas manuales de albañilería y similares.

(3) Nota de la traductora: en las citas textuales se emplea la primera traducción al español, debida a Agustín Bárcenas: Eric R. Wolf. Europa y la gente sin historia. FCE. México 1987. sus bosquejos de modos de producción ordenados conforme al parentesco, tributario y capitalista "ni constituyen tipos en los que las sociedades humanas pueden ser encasillados, ni estadios de la evolución cultural" (Wolf 1982: 100). En su tiempo, esta perspectiva de la Antropología era novedosa tanto por su revisión dinámica del concepto de cultura, como por su construcción de una narrativa histórica específica de lo que había ocurrido globalmente durante los últimos 600 años, los cuales habían transformado tan profundamente las culturas de las gentes que carecían de documentación histórica directa.

Los arqueólogos de la Prehistoria, casi por necesidad, están limitados a reconstruir sus pasados documentados materialmente a partir de una escala macro-histórica. Los intentos de escribir narrativas prehistóricas a gran escala deben complementar los esfuerzos para detectar las regularidades interculturales evolutivas en la conducta humana que subrayan la "unidad psíquica" de la humanidad; la venerada dicotomía en Antropología entre evolución (4) y ciencia, por un lado, e Historia (cf. Kroeber 1935), por el otro, debe enterrarse. Se puede defender que tal reconocimiento está apareciendo sólo ahora.

Durante los años 1960 y 1970 la, entonces, nueva arqueología procesual estaba enfrentada explícitamente con la arqueología histórica (Binford 1972: 114-121), que era considerada particularista e inferior. La primera utilizaba el método científico y buscaba regularidades interculturales válidas que informaran sobre procesos evolutivos culturales importantes, mientras la última, particularmente cuando designaba la "historia cultural", estaba anticuada, constreñida a una fase inicial de la disciplina. El historiador de la cultura realizaba el trabajo básico menos agradecido, organizando las coordenadas espacio-temporales de los datos arqueológicos para crear secuencias arqueológicas indispensables para la explicación teórica posterior. La historia-cultural enfatizaba desarrollos contingentes, particulares, mientras la arqueología procesual era "generalizadora... comprometida con los datos empíricos y destinada a descubrir regularidades en la conducta prehistórica” (Flannery 2006: 12). Los arqueólogos proce-

(4) Salvo una referencia a la convergencia evolutiva en Biología en la sección cinco, final, de este artículo, el término «evolución» se refiere exclusivamente a la evolución social y cultural, no biológica. 
suales normalmente seguían los escritos de Julian Steward $(1949,1955)$ y consideraban la evolución cultural principalmente como un proceso de adaptación de las poblaciones humanas a su medio (cf. Earle 1984: 1-2). El "motor esencial" que dirigía la evolución cultural era el crecimiento inexorable de esas poblaciones (Johnson and Earle 1987: 16).

Hoy, afortunadamente, esta dicotomía está desapareciendo ya que la distinción entre proceso e Historia es borrosa y los sucesos específicos son incluidos -aunque sea esporádicamente- en la interpretación de las secuencias arqueológicas, requiriendo un nuevo "análisis de los acontecimientos" (Beck et al. 2007: 835-836, 856-857). Se reconoce cada vez más que los dos enfoques -proceso e Historia- se complementan uno a otro, una toma de postura que defendió durante largo tiempo Bruce Trigger (cf. sus comentarios en la segunda Lección magistral en Arqueología: Trigger 1991: 563). La búsqueda de paralelos y semejanzas entre sociedades que comparten ciertos rasgos estructurales a menudo es iluminadora, como lo son los rasgos únicos de las diferentes culturas y los contrastes, a menudo significativos, entre ellas. La búsqueda de un orden evolutivo cultural puede detectar semejanzas significativas en el desarrollo o puede allanar la complejidad del pasado más antiguo hasta un esquema, en teoría, ordenado previamente, un espectro evolutivo de desarrollo social graduado de modo continuo que pretende ser diverso y multinear pero que, en realidad, sigue siendo unilineal en el sentido de que todas las sociedades pueden ser clasificadas jerárquicamente de acuerdo con él (cf. Kohl 2005). Inversamente, la celebración de la diversidad cultural y de los rasgos únicos de los desarrollos específicos puede proporcionar una conciencia matizada sobre lo que ocurrió realmente en el pasado o puede dar lugar a una serie confusa de secuencias sucesivas, árboles inacabables perdidos en bosques de dimensiones inciertas.

Pero el rechazo de esta dicotomía y la adopción de ambas perspectivas realmente no es la salida. En Europa y las gentes sin Historia Wolf (1982: 76) insistía en que la evolución cultural "no opera en sociedades aisladas sino siempre en sistemas interconectados en los cuales las sociedades están relacionadas de diversas formas en "campos sociales"'. El concepto central de la Antropología - la cultura- estaba siendo drásticamente revisado y reemplazado en parte por otro mucho más impreciso y amorfo -el de "ámbito social" - un concepto que Wolf había tomado prestado explícitamente de Alexander Lesser, que había desarrollado su concepto en un breve artículo poco conocido, escrito unos 20 años antes. Citemos directamente el artículo de Lesser (1985a: 94-95, 99):

“... adoptemos como hipótesis de trabajo la universalidad del contacto y de la influencia humana como un rasgo fundamental del proceso histórico-social... pensamos que cualquier agregado social no está aislado, separado por algun tipo de muro de los otros, sino que está inextricablemente entrelazado con otros agregados, cercanos y distantes, en el seno de conexiones en forma de telarañas, de red... El concepto de ámbito social tiene una implicación fundamental: las relaciones sociales dentro del ámbito están modelizadas, no son desestructuradas, adventicias o incidentales... el concepto de ámbito, más que el concepto de sociedad como sistema aislado o cerrado, refleja los procesos histórico-sociales de modo más preciso y que el contacto humano y las relaciones interpersonales ajustadas a un patrón no están restringidas a la interacción social dentro de un único agregado social localizado, sino que son una constante universal de la vida social. [El concepto] es particularmente útil para comprender el cambio evolutivo social que ha tenido lugar en la historia humana (5).

\section{MODELOS PREHISTÓRICOS O NARRATIVAS PREHISTÓRICAS}

El concepto de "ámbito social” ¿es útil para la Arqueología prehistórica o es, simplemente, otro término a ser sustituido para detectar las interconexiones entre culturas separadas o cuando se discuten los sistemas de comercio e intercambio? No faltan otros modelos que emplear al esbozar

(5) Más tarde Lesser (1985b: 141): manifestó una perspectiva similar en un amplio ensayo titulado "Antropología y el futuro del internacionalismo": "Los signos del internacionalismo o de la internacionalización a los que me he referido no implican un tipo nuevo o reciente de relación humana. En lugar de ello hay un estado de evolución de la interdependencia e interacción de los grupos humanos, una interdependencia que existió en la vida primitiva inicial y ha estado desarrollándose en alcance e intensidad durante toda la historia humana".

Debe ser recalcado que Lesser desarrolló sus ideas como un americanista que estudiaba sociedades previas al estado y movimientos de continuidad y transformación cultural, tales como la Danza del Fantasma Pawnee. 
las conexiones entre diferentes sociedades; los modelos de "las esferas de interacción", de "la interacción entre unidades políticas paritarias" o de "los sistemas mundiales" vienen inmediatamente a la cabeza. ¿Por qué no usarlos? Para lo bueno y para lo malo ya están santificados en la bibliografía y parecen preferibles al estar definidos de modo más preciso y claro. Esa mejor definición, sin embargo, ¿necesariamente o siempre es una fortaleza? A veces nuestros modelos pueden ser demasiado elegantes y terminan confundiendo más que favoreciendo nuestra comprensión. Examinemos brevemente el bien conocido modelo de los sistemas mundiales y su aplicación a la Prehistoria final de Eurasia.

Como veremos brevemente en nuestra rápida revisión de la difusión de los vehículos con ruedas y de los metales, no es difícil trazar nexos entre culturas diferentes y a través de las regiones contiguas que se extienden por gran parte de la masa terrestre euroasiática durante la Edad del Bronce. Es mucho más difícil evaluar la significación de esas conexiones, determinar la fortaleza de los enlaces entre los componentes del sistema propuesto y creo que el uso del modelo de los sistemas mundiales para comprender las interconexiones de la Prehistoria final a menudo ha sido engañoso y se ha empleado anacrónicamente. La Edad del Bronce de Eurasia no estaba estructurada de modo sistemático en centros, periferias y semi-periferias como se postuló para el mundo moderno a partir del siglo XVI d.C. (Wallerstein 1974). Una documentación convincente sobre el intercambio desigual, en el mejor de los casos, es problemática. No hubo un desarrollo sistemático del subdesarrollo ni, con quizás algunas excepciones, hubo dependencias creadas de manera deliberada y mantenidas de modo consistente como las supuestamente características del sistema mundial moderno.

Los agricultores y ganaderos, no los comerciantes y herreros, fueron los habitantes principales de la Edad del Bronce. En el transcurso del tiempo la economía ganadera de la Edad del Bronce de las estepas se volvió crecientemente especializada, culminando en la aparición de un verdadero nomadismo montado pastoril con rebaños mixtos de caballos adaptados al frío, ovejas, cabras, vacas y camellos bactrios a comienzos de la Edad del Hierro. En cierto sentido, con un desarrollo especializado de ese tipo, los mundos tan diferenciados de la estepa y del cultivo quedaron separados todavía más en función de sus estilos de vida contrastantes. La llegada del hierro también anunció la ruptura de las interconexiones necesarias para la obtención del cobre y estaño que fueron características de la Edad del Bronce y, al menos inicialmente, pudo haber llevado a una reducción en la escala de la producción intensiva y del intercambio de objetos de metal y a la aparición de talleres independientes a menor escala dedicados a la producción de hierro (cf. también McConchie 2004: 146-148; 163-166).

Dos mundos, el "civilizado" del Próximo Oriente Antiguo con un foco principal, aunque en absoluto exclusivo, hacia alguna forma de agricultura intensiva (aterrazado, irrigación, etc.) y las estepas euroasiáticas occidentales "bárbaras" con economías ganaderas móviles y, presumiblemente, alguna dependencia de la recolección intensiva, si es que no del cultivo de cereales (aunque su naturaleza y alcance permanecen confusos) interactuaron crecientemente dentro y entre cada región complementaria durante todas las épocas de la Edad del Bronce. Los pastores se movieron a lo largo de los valles fluviales, así como por la estepa abierta, construyendo kurganes elevados e intercambiando objetos ceremoniales y de prestigio y cada vez mas, en el curso del tiempo, instrumentos y armas. El Próximo Oriente Antiguo estuvo interconectado mediante redes de intercambio más elaboradas todavía, así como por alianzas políticas y conquistas o incursiones para alcanzar -aunque esporádicamentela hegemonía política y para obtener bienes exóticos de prestigio y satisfacer sus necesidades: en particular instrumentos metálicos y armas. Estos "mundos" fueron distintos aunque interconectados no sólo a través del intercambio de materiales, en especial metales, sino también por los desplazamientos continuos de pastores esteparios por el mundo agrícola sembrado del Próximo Oriente.

Esta red de interconexiones durante la Edad del Bronce, sin embargo, no se singularizó como una unidad, como una versión rudimentaria del moderno "sistema mundial" (Ratnagar 2001). Nuestros modelos del pasado prehistórico son necesariamente parciales y provisionales; no deben asumir una realidad que no poseen. Algunos teóricos de los sistemas mundiales han universalizado, eficazmente, la presencia de tales sistemas, postulando "redes político-militares" y "redes de bienes de prestigio" de una jefatura compleja, de 
tipo Gran Hombre, nómada, forrajeadora, y de otros "sistemas mundiales" documentados etnográficamente que se contrajeron y expandieron o "brillaron de modo intermitente" en el curso del tiempo (Chase-Dunn y Hall 1995: 110-113). Así redefinidos, estos sistemas mundiales recuerdan superficialmente, quizás, el concepto de los "ámbitos sociales" de tipo reticular, universalmente presentes, empleados de modo tan fructífero por Wolf en Europa y las gentes sin Historia.

Pero aquí se ha instalado la confusión terminológica. Tal expansión universalizada de los sistemas mundiales priva esencialmente de cualquier poder explicativo específico al sistema mundial moderno, cualitativamente distinto, de Wallerstein que está caracterizado por los principios del intercambio desigual y del desenvolvimiento del subdesarrollo. ¿Son los "sistemas mundiales" del Paleolítico superior o, al menos, del Mesolítico directamente comparables con el de la era histórica moderna? Semejante perspectiva ¿es realmente útil? ¿Por qué no referirnos a los procesos de globalización que afectan los desarrollos durante, digamos, las Revoluciones Neolítica o Urbana? La cuestión básica que hay que preguntarse es ¿qué se gana con el uso de la terminología y los conceptos de los sistemas mundiales, incómodos y, a menudo, malentendidos? ¿Por qué no trazar, simplemente, las interacciones entre regiones sin aludir a esos términos universalizados y engañosamente cosificados?

En resumen, la referencia a un sistema mundial de la Edad del Bronce debe iluminar, no equivocar, nuestra comprensión del alcance de la integración e interacción logradas durante los milenios IV AC al II AC. Una de las fortalezas del modelo de los sistemas mundiales es su foco sobre la unidad relevante de análisis, es decir, sobre el área cuyo grado de interacción económica y política es tal que justifica su consideración como un sistema en el que los cambios en una parte provocan cambios o desarrollos por todo el sistema. Desde esta perspectiva, argumentaría que Sumer y los estados secundarios que emergieron al Este de Sumer durante las últimas centurias del III milenio AC y las primeras centurias del II milenio AC constituyeron alguna forma de "sistema" interconectado, aunque sus límites occidental y septentrional son más difíciles de definir. Los límites del sistema también cambiaron en el curso del tiempo de una manera que refleja no simplemente un crecimiento continuo, si no el desarrollo consciente de nuevas áreas de intensa interacción, tales como la cuenca mediterránea oriental, extendiéndose hasta Europa central, durante la primera mitad del II milenio AC, como han mostrado recientemente Parkinson y Galaty (2007). Simultáneamente, muchos de los estados secundarios al Este de Sumer colapsaron o decayeron $\mathrm{y}$, al menos temporalmente, se retiraron de este "sistema".

La adopción del modelo de los sistemas mundiales para explicar tales desarrollos ¿es útil o equívoca? La analogía entre la Edad del Bronce y los tiempos modernos puede ser más útil para revelar diferencias estructurales básicas que para descubrir semejanzas superficiales, engañosas (Kohl 1989; Stein 1999). Desgraciadamente, los teóricos sociales y los arqueólogos tienden a abusar de los modelos que desarrollan (cf. discusión en Kepecs y Kohl 2003). Los defensores del modelo de los sistemas mundiales pueden quedar enredados en argumentos interminables, esencialmente tipológicos sobre las áreas que constituyen los centros, semi-periferias, periferias y otras idiosincráticamente pretendidas unidades (por ejemplo, los casi-centros) del sistema definido. Irónicamente, tales debates se convierten en ejercicios clasificatorios, comparables al proyecto de los neo-evolucionistas de nivelar sus sociedades como tipos siempre refinados y matizados de jefaturas y estados iniciales. Cuando esto sucede, cualquier utilidad que tuviera el modelo de los sistemas mundiales se disipa en gran medida. La simple construcción de una narrativa macro-histórica que enfatiza las interconexiones entre las diferentes regiones es más directa y menos confusa que el forzado encasillamiento de los agregados sociales en categorías abstractas del análisis de los sistemas mundiales.

Aunque las fronteras que delimitaban los "mundos" bárbaro y civilizado (no los sistemas mundiales) eran porosas, las diferencias en su estructura global y en los métodos de interacción eran chocantes. Una revolución urbana había tenido lugar en Mesopotamia en la cual, durante un tiempo, en particular durante todo el III milenio $\mathrm{AC}$, aparentemente mucha más gente vivió en grandes ciudades, formando núcleos, que en el campo y la estratificación social marcada y la especialización de las actividades emprendidas por la población son evidentes en los registros tanto arqueológico como cuneiforme. Hacia el final del III milenio AC este núcleo urbano había estimu- 
lado el surgimiento de estados secundarios o de unidades políticas regionales complejas hacia el Este, y una compleja red de intercambio y alianzas políticas cambiantes, establecidas pacíficamente y por la fuerza, había emergido, uniendo o integrando toda este área en alguno tipo de sistema entrelazado a través del cual materiales, tecnologías y símbolos de contenido ideológico fueron ampliamente compartidos o, al menos, reconocidos.

Es más difícil construir el mundo de la Edad del Bronce "bárbara" de las estepas al norte en buena medida debido al hecho de que era iletrado, careciendo de fuentes históricas que facilitaran la reconstrucción de sus rasgos sociales. El registro arqueológico que ha sido compilado, además, es deficiente por su excesivo énfasis en los restos funerarios y sus relativamente escasos datos de los hábitats. Hoy este cuadro está cambiando, ya que los poblados están siendo descubiertos vía toda una variedad de nuevos medios y excavados, aunque el panorama a mano por el momento sigue siendo fragmentario faltando algunas piezas vitales para completar el rompecabezas. Diferentes gentes interactuaron unas con otras principalmente no como comerciantes, sino como pastores; esto es, las economías ganaderas móviles que eran características de las estepas pusieron a gentes diferentes en contacto continuo unas con otras. Este contacto continuo estimuló presumiblemente los desarrollos políticos, tanto la formación como la disolución, de grandes alianzas y confederaciones de gentes relacionadas que hicieron posible la siempre creciente extracción a gran escala de los minerales metálicos y la casi universalmente compartida habilidad de producir e intercambiar herramientas y armas metálicas.

El modelo de los sistemas mundiales no puede abarcar esos dos mundos contrastantes de la Edad del Bronce; las estepas de Eurasia no son una periferia de un centro del Próximo Oriente Antiguo. El concepto de los ámbitos sociales de tipo reticular, superpuestos y abiertos requiere mucho menos, nos exige sólo ampliar nuestros horizontes más allá de la cultura o el estado local y mostrar cómo los desarrollos culturales arqueológicamente visibles, tales como los avances tecnológicos, son compartidos a través de amplias áreas que, en último término, se expanden en el tiempo. Aunque reconocidamente impreciso, el concepto de ámbito compartido es, argumentaría, más congruente con la naturaleza de grano grueso del registro arqueológico y, como tal, más apropiado para intentar construir narrativas prehistóricas a gran escala, una tarea central en la que debemos comprometernos.

\section{LA NATURALEZA MATERIAL DE LA EVIDENCIA ARQUEOLÓGICA}

La consideración de la naturaleza material de la evidencia arqueológica también sugiere que estos modelos que recalcan lo que la gente realmente hizo en el pasado -cómo subsistieron y lo que produjeron- son más apropiados que aquellos orientados hacia lo que la gente pensaba, los valores que mantuvieron o las ideologías que les motivaron. Esta afirmación no es tanto filosófica -insistiendo en que las explicaciones materialistas son, en último término, más satisfactorias y explicativas-. Más bien es un simple reconocimiento de la naturaleza material y, en ausencia de textos, muda condición del registro arqueológico, así como de que los símbolos físicos con una carga ideológica que, ocasionalmente, son accesibles en el registro, son -al faltar una referencia escrita explícita- polivalentes, encarnando significados múltiples $\mathrm{y}$, a veces, incluso contradictorios.

Los arqueólogos deben reconstruir el pasado sobre la base de la evidencia que controlan mejor. Dada la naturaleza de los restos de la cultura material, esto significa que el énfasis principal debe ponerse en la reconstrucción de las antiguas tecnologías, del medio ambiente, de la subsistencia y de las economías de intercambio y, a medida que la evidencia lo permite, en la organización y estructura social, tal como, indirectamente, se reflejaron en el paisaje, en los patrones de asentamiento, en la arquitectura, en la evidencia funeraria, y en cosas por el estilo. Los símbolos, las creencias y las ideologías de las gentes que crearon el registro arqueológico ciertamente no deben ignorarse; la consciente, ideológicamente orientada y simbólica producción y manipulación de los materiales, que son tan importantes hoy, tienen que haber sido de una relevancia crítica también durante los primeros tiempos. El historiador cualificado del arte o el arqueólogo, por supuesto, pueden interpretar plausiblemente algunos objetos cargados de simbolismo con ricas presen- 
taciones iconográficas. Por ejemplo, incluso un análisis rápido de la famosa estela de la victoria de Naramsin no sólo muestra que algunos individuos tenían un mayor rango o que eran más poderosos que otros, sino también revela que la figura mayor que la de tamaño natural de Naramsin, llevando un casco con cuernos, encubre ciertas aspiraciones divinas, y que tal concepción de la realeza es, sin duda, significativa para comprender el Imperio Acadio y las acciones de sus dirigentes.

Otras veces, sin embargo, las representaciones son menos claras o abiertas a interpretaciones múltiples. En tales casos, puede ser en gran parte un esfuerzo perdido intentar interpretaciones demasiado específicas de los valores silenciosos y creencias de las gentes prehistóricas que nunca registraron (es decir, de forma escrita) los significados precisos representados en los objetos materiales. Como ilustración, consideremos la maravillosa copa de plata (Lám. I) que fue encontrada en un rico kurgan en el cementerio Karashamb, al norte de Ereván, Armenia a fines de los 1980. Su increíble iconografía ha sido tema de muchas interpretaciones desde la historia del arte y la
Arqueología. ¿Por qué no? Las escenas representadas son tan vivas que casi de modo natural provocan comentarios especulativos: tipos de armas y escudos; escenas de combate/decapitación; montones de cabezas humanas. La representación del pájaro con cabeza de león, un ser fantástico, que también aparece en otros objetos con carga ideológica distribuidos ampliamente por toda Mesopotamia y otras áreas del Próximo Oriente Antiguo, sugiere conexiones con un mundo más amplio de significados o conocimientos compartidos. La copa muestra claramente que los tiempos eran violentos, pero ¿conmemora una victoria específica de un grupo sobre otro, posiblemente una victoria mesopotámica sobre una jefatura local, o al revés? ¿un día normal o excepcional en un Cáucaso infestado de conflictos? ¿Quién sabe? El segundo registro representa algo que imita y copia conscientemente una escena procesional mesopotámica clásica, que culmina en una figura principal, a tamaño mayor que el natural, que recibe regalos y está siendo abanicada, mientras escucha la música de un harpista situado tras ella. Muy probablemente, estamos viendo aquí a

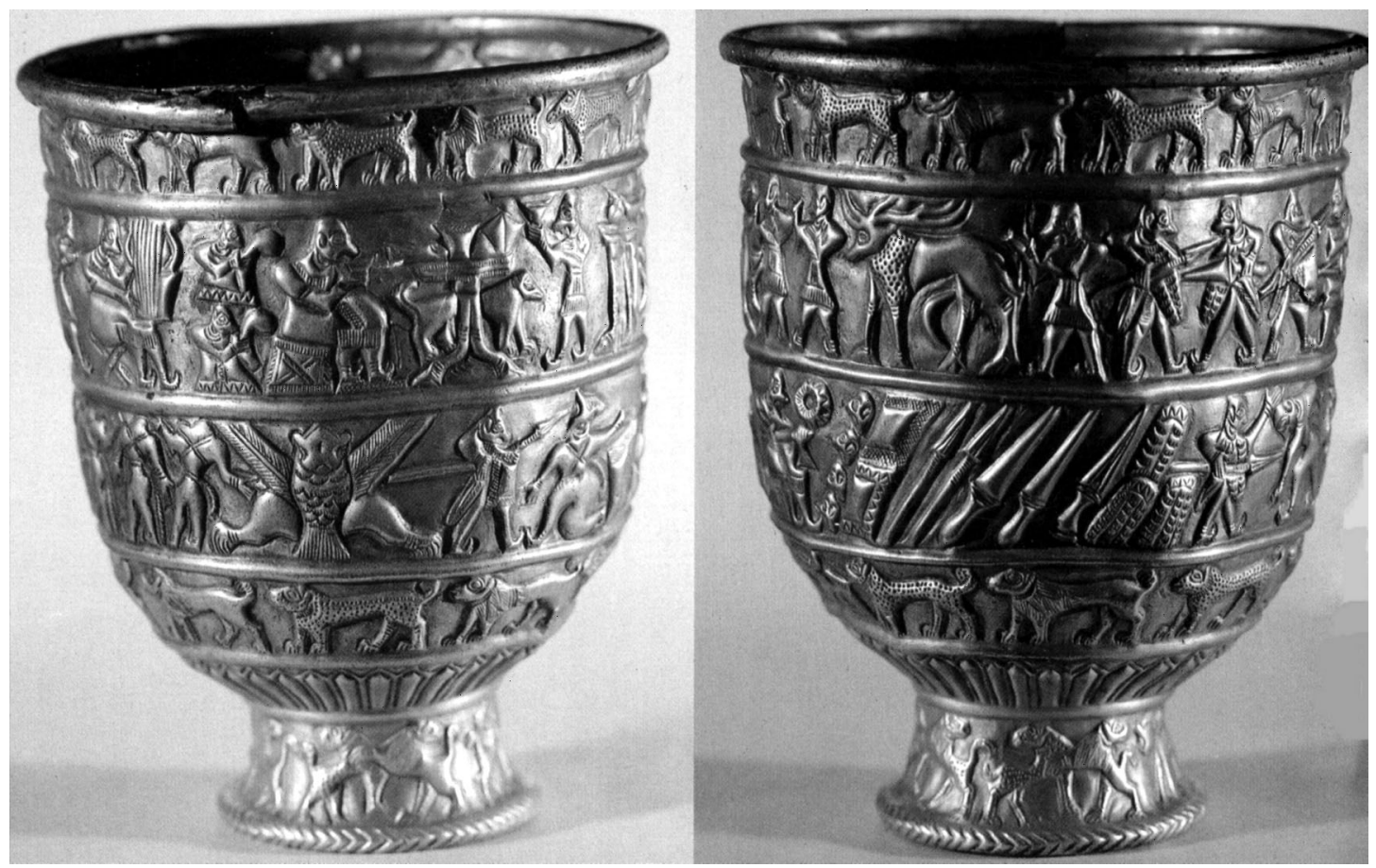

Lám. I. Copa de plata de Karashamb: un jefe caucásico con aspiraciones de "rey” sumerio (Lugal) (adaptación a partir de Kohl 2007: 116). 
un "jefe" local del Cáucaso meridional que aspira a un rango social incluso mayor, una especie de pretendiente a lugal sumerio o "rey". Los estudiosos han intentado distinguir más significados a partir de este objeto fabuloso, pero es mejor contenerse; pretender ir mucho más allá es, en gran medida, un empeño especulativo, aunque estimulante. En resumen, los modelos que los arqueólogos conciben, aunque elegantes y teóricamente satisfactorios, tienen que estar limitados, en último término, por los restos de la cultura material, muy refractarios y opacos, que constituyen el registro arqueológico.

En Europa y las gentes sin Historia, Eric Wolf definió parsimoniosamente tres "modos de producción" -ordenado conforme al parentesco, tributario y capitalista- que operaron en ámbitos sociales compartidos y que le permitieron construir su gran narrativa histórica de los últimos 600 años. El concepto de "modo de producción" unió política y economía y mostró cómo el trabajo social se movilizaba para transformar la naturaleza. La historia que Wolf trazó puso en evidencia cómo las sociedades, al desplegar el trabajo social, de diferentes modos se pusieron en contacto entre sí y se transformaron unas a otras, creando el mundo en el que vivimos y proporcionando engañosamente, al menos a una primera generación de antropólogos, unas culturas incontables y, en apariencia, aisladas que estudiar. Su trabajo destruyó eficazmente esa última ilusión.

¿Qué sucede, entonces, con el concepto de "modo de producción" a la hora de reconstruir la Prehistoria sobre la base de los restos materiales? Aquí también puede estar justificada alguna precaución. El concepto de modo de producción también exige demasiado o es demasiado elegante para unos objetivos estrictamente arqueológicos. Sin duda es algo que hay que procurar conseguir, pero algo cuyos requisitos no estrictamente materiales también deben ser reconocidos. Para adoptar una antigua terminología familiar: las fuerzas de producción son más visibles y recuperables arqueológicamente que las relaciones de producción, siendo ambas esenciales para trazar de modo satisfactorio cómo se desplegó realmente el trabajo social. La documentación arqueológica de cuáles cosechas crecieron y qué animales se pastorearon, ¿nos permite comprender también las disposiciones sociales críticas que dirigieron y condujeron tales actividades? En algunos casos, como las pinturas murales funerarias egip- cias (con la ayuda de documentos históricos) quizá la respuesta sea sí, pero en muchos otros la tarea es mucho más difícil. Lo mismo que al reconstruir las ideologías pasadas y los valores, determinar cómo se puso en práctica el trabajo puede exigir demasiado de la naturaleza de la evidencia arqueológica.

La dificultad no debe disuadir el esfuerzo, pero la complejidad inherente a la tarea también debe ser reconocida siempre sin impedir subrepticiamente que aparezca. Sin embargo una afirmación sensata no lleva, necesariamente, a desesperarse. Las limitaciones del registro arqueológico son reales pero no llegan al extremo de impedir reconstruir los contornos generales de los desarrollos históricos a gran escala. La habilidad de los arqueólogos para reconstruir las tecnologías antiguas, el medio ambiente, la antigua subsistencia y las economías de intercambio es suficiente para detectar pautas específicas a gran escala y procesos, para escribir, en esencia narrativas macro-prehistóricas con fundamento empírico.

Costó la mayor parte del siglo XIX que la idea de "prehistoria" - una explicación coherente, significativa del pasado, basada exclusivamente en los restos materiales y sin fuentes escritas, fuera aceptada o, básicamente, que se reconociera que los datos arqueológicos eran un registro real de las actividades humanas pasadas que tenía que ser ordenado e interpretado por el prehistoriador. Este registro puede o no ser iluminado usando modelos abstractos, tales como el análisis de los sistemas mundiales, pero inevitablemente tendrá que ser ordenado en función de su temporalidad, de la secuencia de acontecimientos seleccionados por el prehistoriador según criterios implícitos o explícitos de significación. La Prehistoria, como la Historia, está necesariamente preocupada por trazar el movimiento de los sucesos pasados o por la reconstrucción de las actividades pasadas a través del tiempo o a través de su "inexorable secuenciación" (Evans 1997: 134). La principal forma de hacerlo es construyendo una relación o narrativa de estos sucesos en el orden en que sucedieron. Citando a Keith Windschuttle (1997: 217):

"El historiador [o prehistoriador] no tiene, en absoluto, que creer que la Historia tiene algun propósito... para seguir dependiendo todavía de la técnica de la narrativa... [que es]... una representación de la realidad... Lo que sucede en la Historia no es en absoluto azaroso o caótico. Cualquier 
cambio importante en la Historia [o Prehistoria] depende de, es decir, es contingente respecto a todo lo que llegó antes".

Se puede argumentar que la construcción de tales narrativas constituye una de las principales tareas que los arqueólogos deben emprender. Vamos a intentar demostrar esta aserción considerando dos desarrollos interrelacionados de la Edad del Bronce en Eurasia: la emergencia y difusión de los vehículos rodados y la aparición y propagación de las herramientas de metal y las armas.

\section{DIFUSIÓN DE LAS TECNOLOGÍAS}

En tanto futuros descubrimientos puedan alterar nuestro conocimiento, actualmente la evidencia más antigua de vehículos rodados se fecha aproximadamente a mediados del IV milenio AC y está documentada de modo convincente en un amplia área, que abarca desde Europa septentrional (Alemania y Polonia), a Ucrania central y la región Kuban del Cáucaso noroccidental y las estepas rusas meridionales, a Anatolia oriental y Mesopotamia septentrional (Bakker et al. 1999; más detallado en Burmeister 2004; Primas 2007) (Lám. II). Algo después, hacia fines del IV milenio, representaciones de trineos con ruedas y carretas aparecen en las tabletas pictográficas de Uruk (IV A) en Mesopotamia meridional. Cabe argumentar que la evidencia más antigua y mejor datada y convincente procede de Europa septentrional (surcos paralelos de ruedas rastreables unos $20 \mathrm{~m}$ en Flintbeck, Alemania, y el dibujo de una carreta sobre una cerámica de Bronocice, Polonia, fechada con seguridad); otras evidencias tales como la aparición de figuritas animales con perforaciones en sus patas para la posible inserción de ejes (similares a las figuritas animales con ruedas precolombinas de México) en contextos de la cultura Tripolye son menos seguras, aunque es probable que los bueyes fueran uncidos a los arados, al menos, en los estadios finales de esta cultura calcolítica.

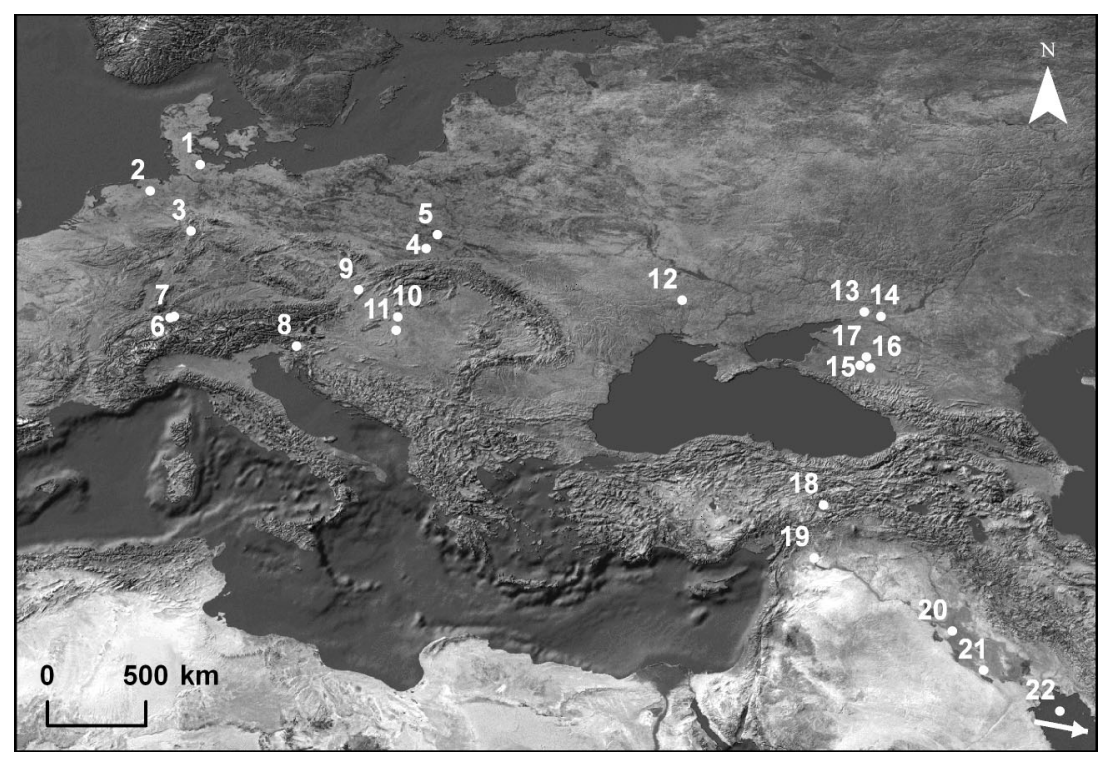

Lám. II. Área de distribución de los primeros vehículos rodados: 1 Flintbek (huellas de carro); 2 Moorweg XV (Le) (eje); 3 Lohne-Züschen, 4 Bronocice y 5 Ostrowiec (sellos con representaciones de carros); 6 Zürich-Seerosenstraße (eje); 7 Zürich-Akad (rueda maciza); 8 Stare gmajne (eje y rueda maciza); 9 Radošina, 10 Budakalász y 11 Szigetszent-márton (maqueta de carro); 12 Cultura Tripolye (figuritas de terracota sobre ruedas); 13 Koldyri (rueda maciza); 14 Konstantinovskoe (maqueta de rueda), 15 Čišcho, 16 Psekujchabl' (maqueta de rueda); 17 Starokorsunskaja (rueda maciza); 18 Arslantepe y 19 Ğebel Arūda (maqueta de rueda); 20 Tell al-’Uqēr y 1 Uruk (sellos con representaciones de carros); 22 Harappa (maqueta de carro). La evidencia más antigua fechada con seguridad procede del norte (n. ${ }^{\circ} 1$ a 4), después del Este (n. $\left.{ }^{\circ} 12\right)$ y, más tarde, del Sur (n. ${ }^{\circ} 20$ y 21) (adaptación a partir de Burmeister 2004: 17, Abb. 3). 
La cuestión de los orígenes últimos que es siempre difícil de comprobar de modo preciso sobre la base de la evidencia arqueológica es, sin embargo, menos significativa que la muy rápida propagación o adopción de esta innovación a través de este amplia área o ámbito social compartido por culturas marcadamente diferentes en niveles variados de desarrollo social y tecnológico. Supera la imaginación concebir esas adopciones como algo que no fueran desarrollos compartidos.

Un poco después, a fines del IV milenio e inicios del III AC, el uso de vehículos rodados a gran escala está inequívocamente documentado por la aparición de carretas con ruedas de madera tripartitas en enterramientos de las denominadas culturas Novotitorovskaia y Katakombnaia de la llanura Kuban en el Cáucaso noroccidental y las estepas rusas meridionales adyacentes, respectivamente. Más de 250 de tales enterramientos con carretas con, por otro lado, muy poca evidencia de diferenciación social han sido excavados en túmulos (kurganes), sugiriendo con fuerza que el uso de carretas en estas culturas era amplio y probablemente relacionado con su adopción de una economía pastoril más móvil. Algo más tarde, hacia mediados del III milenio, carretas tiradas por bueyes aparecen en un pequeño número de kurganes monumentales construidos de manera elaborada en el Cáucaso meridional, alguno de los cuales contenía también vasos de plata y de oro y joyería. Aproximadamente a la vez, carretas tiradas por bueyes, como las del famoso pozo funerario de Ur, se encuentran en las tumbas reales de Mesopotamia meridional, una práctica que ha sido ahora documentada también en los enterramientos denominados "reales" excavados en Gonur-depe en Turkmenistan meridional (Kohl 2007: 196-199). También es de notar que los camellos bactrios pueden haber tirado inicialmente de tales carretas en Asia central.

A una innovación, que aparentemente sirve a objetivos funcionales en algunas culturas relativamente indiferenciadas de las estepas de Eurasia, se le concede un valor de prestigio superior en otras unidades políticas más complejas del Próximo Oriente Antiguo. Pronto los carros tirados por caballos con rueda radiada, mucho más móviles y significativos desde el punto de vista militar, se extenderán rápidamente desde las estepas por todo el Próximo Oriente Antiguo hasta China durante la Edad del Bronce (Anthony 2007).
Otro ejemplo de tecnologías compartidas interrelacionadas es proporcionado por la distribución de herramientas y armas similares de metal por todas las, denominadas por el arqueólogo ruso E.N. Chernykh (1992), provincias metalúrgicas. La provincia metalúrgica es una categoría integradora destinada a ordenar el registro arqueológico sobre la base, principalmente, de una uniformidad tipológica general (o "estándares") de los instrumentos y armas de metal y de la semejanza fundamental en la tecnología de producción de los útiles y armas de metal que incluye. El concepto de "provincia metalúrgica" tiene la gran virtud de haber sido construido directamente sobre la base empírica de los análisis de decenas de miles de artefactos metálicos.

Según Chernykh, tales "provincias metalúrgicas" fueron pocas. Él pudo definir sólo siete en la antigua Unión Soviética, durante la "Primera Edad del Metal". Las provincias se vuelven también más extensas con el transcurso del tiempo, incorporando al final la mayoría de Eurasia. La primera de tales "provincias metalúrgicas", cualitativamente distintas, fue definida como la Provincia Metalúrgica Cárpato-Balcánica que abarcaba desde los Balcanes septentrionales al Volga medio e incluía distintos "focos": los Balcanes septentrionales, Transilvania y el área del Danubio central, los Cárpatos septentrionales, la región occidental del Mar Negro y las estepas de Eurasia occidental entre los ríos Dnieper y Volga. Las innovaciones en el trabajo del metal de la PMCB estaban integradas en las espectaculares culturas calcolíticas de Europa suroriental o en lo que M. Gimbutas (1989) llamó "Vieja Europa". Aparentemente desaparecieron o colapsaron durante el primer cuarto del IV milenio AC, un fenómeno, al que sucedió la aparición de la nueva Provincia Metalúrgica Circumpóntica que se extendía desde la Edad del Bronce Antiguo al Medio y que, al menos inicialmente, estaba focalizada en la producción de cobres/bronces arsenicales del Cáucaso (Fig. 1).

La propagación de las tecnologías del trabajo del metal se traza primero de Oeste a Este, a través de las tierras de Eurasia, pero este patrón se vuelve mucho más complejo durante el II milenio AC cuando útiles y armas de bronce/estaño, hermosamente trabajados y muy específicos o diagnósticos, aparentemente se extienden en dirección inversa, Este a Oeste, y aparecen mucho más al norte en las zonas forestales y de estepa arbola- 


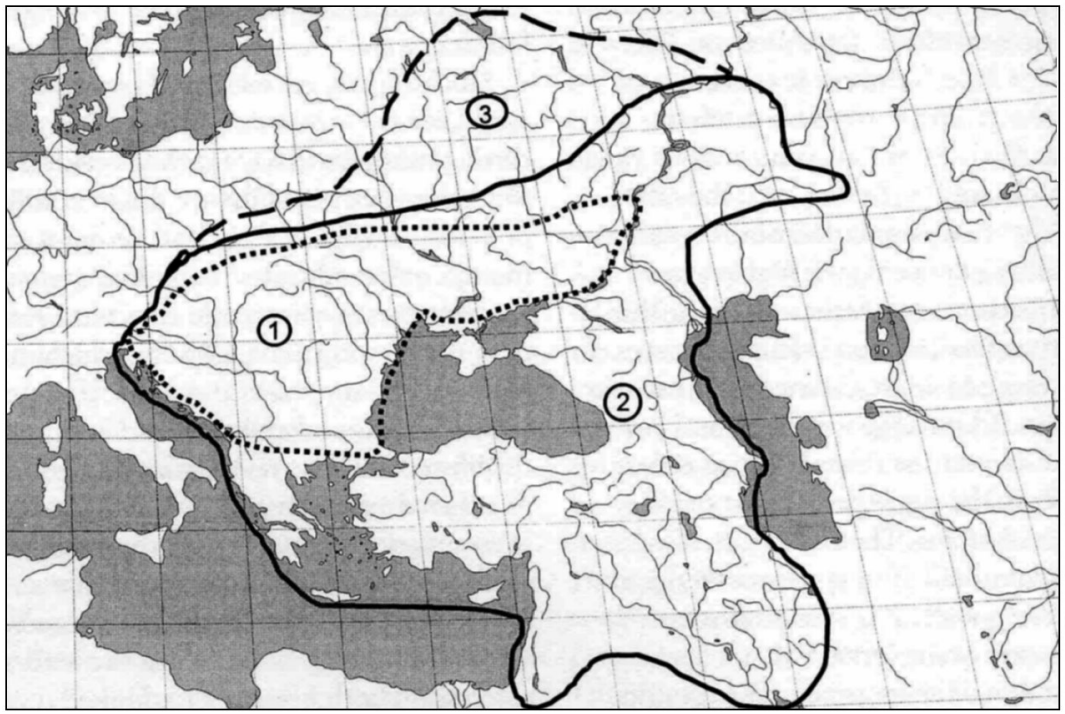

Fig. 1. Provincias Metalúrgicas en Asia occidental durante el Calcolítico y la Edad del Bronce Antiguo y Medio: 1) Provincia Metalúrgica Cárpato-Balcánica, c. 5000-3800 AC; Provincia Metalúrgica Circumpóntica de la Edad del Bronce Antiguo (2) y Medio (3) c. 3600-1900 AC (adaptación a partir de Kohl y Chernykh 2003: 31).

da de Eurasia septentrional (p.e., el "fenómeno transcultural" Seima-Turbino de la Edad del Bronce Final, cf. Chernykh 1992: 215-234). Los bienes de prestigio también fueron intercambiados a través de las contiguas pero distintivas Provincias Metalúrgicas Europea, Caucásica, Euroasiática y de Asia central de la Edad del Bronce Final, y estas conexiones puede trazarse también a través de comunidades histórico-culturales definidas, amplias y que se solapan arqueológicamente, como las comunidades de las Tumbas de Madera (Srubnaia) y Andronovo.

P. Zidarov (2005) recientemente ha intentado rebajar la fecha del famoso Tesoro L de Troya, comparando sus masivas hachas de piedra de nefrita, jadeita y lazurita (Lám. III), algunas de las cuales pesa unos $2 \mathrm{~kg}$, con las del depósito de Borodino (Besarabia, Moldavia) que pueden ser fechadas con confianza desde mediados al tercer cuarto del II milenio AC, a partir de sus paralelos metálicos, tanto con el complejo Seima-Turbino, como con los ricos enterramientos micénicos de Grecia. Hachas, cuidadosamente realizadas y pulimentadas, aparecen en contextos incluso más antiguos en las estepas occidentales de Eurasia y en el Cáucaso septentrional, pero las notables correspondencias en forma y material entre los depósitos de Borodino y Troya parecen apoyar la datación inferior revisada de Zidarov. Las hachas
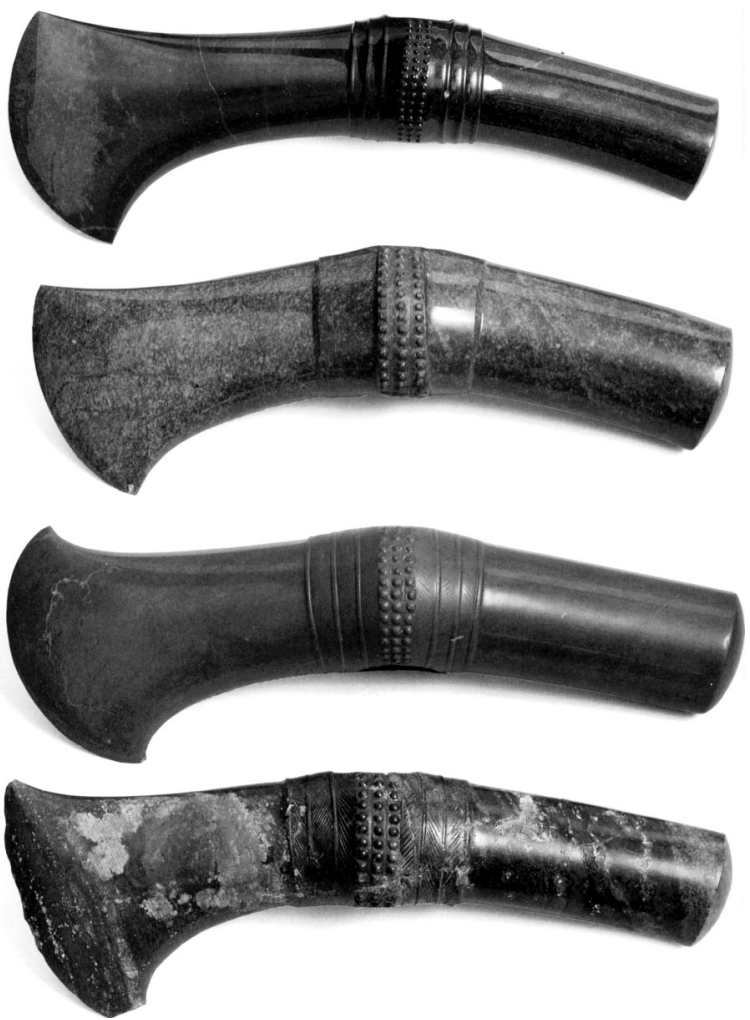

Lám. III. Hachas-martillo de nefrita, jadeita y lazurita de Troya, Tesoro L (adaptación a partir de Tolstikov y Treister 1996: 148).

T. P., 66, N. ${ }^{\circ}$, julio-diciembre 2009, pp. 7-23, ISSN: 0082-5638 doi: $10.3989 /$ tp.2009.09027 
de nefrita y jadeita de los dos depósitos son visualmente indistinguibles y es bastante posible que ambas puedan haberse originado más al Este, en las montañas Sayan de Siberia o en el noroeste de China. El lapislázuli en esta época puede haber procedido de los depósitos conocidos en la región del lago Baikal. Tales piezas ceremoniales o símbolos de poder posiblemente llegaron al final de su viaje a Troya, que estaba estratégicamente situada en la cabeza de los Dardanelos, vía una ruta marítima a través del Mar Negro, junto con útiles de metal funcionales parcialmente procesados y armas. A mediados del II milenio la mayoría de la zona esteparia y de la estepa arbolada de Eurasia estaba repleta de grandes comunidades culturales interrelacionadas (como las Srubnaia y Andronovo) y provincias metalúrgicas separadas que se superponían, abarcando esencialmente hacia el Este hasta las fronteras de China.

Las más recientes investigaciones de Chernykh en la región de Kargaly, de unos $500 \mathrm{~km}^{2}$ en los Urales suroccidentales, cerca de Orenburgo, han demostrado que sus depósitos de metal fueron explotados a gran escala, si es que no a escala industrial, durante la Edad del Bronce Final o, aproximadamente, a mediados del II milenio AC (un breve resumen en inglés de estas investigaciones en Kohl 2007: 170-180). El equipo ha excavado lo que es, claramente, un poblado de mineros del final de la Edad del Bronce en un sitio llamado Gorny dentro del complejo Kargaly con evidencia indiscutible de actividades mineras. Un descubrimiento inesperado fue la colección de unos 2.300.000 restos de fauna procedentes del área excavada de unos $1.000 \mathrm{~m}^{2}$ de los cuales en torno a un $80 \%$ fueron identificados como huesos de vaca. Semejante colección es difícil de comprender o explicar. La única certeza es que es imposible tratar Kargaly o el poblado minero excavado de Gorny aisladamente; más bien ambos comparten amplios "ámbitos sociales" interconectados con otras gentes relacionadas con las Srubnaia, todas las cuales estaban implicadas en un proceso histórico más amplio.

Materiales y tecnologías se difundieron a través de Eurasia durante la Edad del Bronce. Aunque ello puede ser claramente documentado, hay que plantear una advertencia importante. El reconocimiento de interconexiones compartidas y de transferencias tecnológicas no nos dice cómo sucedieron tales desarrollos, ni qué pretendían con ello las sociedades locales específi- cas. Nuestro análisis tiene que integrar ámbitos sociales ampliamente compartidos, macro o casi continentales, con desarrollos locales o más regionales. Los vehículos rodados fueron usados por diferentes sociedades para propósitos distintos: parecen haber sido un componente integral de las culturas de pastores de ganado vacuno que se extendieron por las estepas occidentales de Eurasia durante la Edad del Bronce y se han encontrado allí por decenas. En el Cáucaso meridional y el Próximo Oriente Antiguo hacia el sur, sin embargo, aparentemente fueron mucho menos comunes durante todo el IV y la mayoría del III milenio AC, un exótico elemento de prestigio empleado para acompañar a los jefes locales o las élites estatales y a la realeza en el más allá.

Es un primer paso útil definir amplias provincias metalúrgicas, que comparten equipos de útiles funcionales similares y armamento, pero nos queda todavía un largo camino para comprender cómo funcionaron realmente esos sistemas de producción e intercambio. ¿Se trató de minerales metálicos, en gran medida sin procesar, acarreados a distancia en vehículos rodados tirados por bueyes desde los sitios mineros primarios, como Kargaly? Como Chernykh (1997: 69) propone, ¿las vacas estuvieron intercambiándose por minerales metálicos, dando lugar a la increíble concentración de sus restos en el sitio Gorny? ¿Cómo funcionaría tal sistema? ¿Quién dirigió el proceso? Simplemente no lo sabemos y no lo sabremos hasta que una información más básica sobre la estructura social y la organización de las comunidades de las Tumbas de Madera haya sido mejor documentada arqueológicamente mediante la investigación de más asentamientos y no sólo mediante la excavación continuada de kurganes.

\section{CONCLUSIÓN: IMPLICACIONES PARA UNA PRÁCTICA ARQUEOLÓGICA CONTEMPORÁNEA}

¿Qué regularidades o patrones podemos observar cuando trazamos la propagación de los vehículos rodados y de economías más móviles de pastores de ganado vacuno a través de Eurasia occidental o cuando documentamos la adopción compartida de tecnologías de trabajo del metal y la utilización de tipos similares de útiles y armas en la mayor parte de esta misma extensa área? El 
concepto de unos ámbitos sociales compartidos siempre en expansión y siempre abiertos ¿es útil en nuestra búsqueda de una mejor explicación de estos desarrollos? Ampliar nuestros horizontes espaciales más allá de las culturas individuales o, incluso, más allá de los "sistemas mundiales" integrados hace más difícil detectar progresiones regulares o trayectorias evolutivas desde unas formaciones sociales relativamente simples a otras más complejas.

Un área puede experimentar un crecimiento, como el Cáucaso con el surgimiento de la Provincia Metalúrgica Circumpóntica, mientras otra región, desde los Balcanes hasta Ucrania oriental, colapsa o declina, procesos oscilantes o intermitentes que han sido señalados por teóricos de los sistemas mundiales (p.e., Chase-Dunn y Hall 1997). De modo similar en el II milenio AC, sociedades en el Mediterráneo oriental, en Chipre, Creta, la Grecia continental y en otras partes florecieron, participando en una compleja red de intercambio con orientación marítima en la que los bienes preciosos exóticos, los bronces acabados o semiprocesados, y los bienes de subsistencia circularon libremente (Parkinson y Galaty 2007), mientras en otras partes los estados secundarios complejos y las unidades políticas regionales al Este de Sumer habían colapsado, descendiendo a una edad oscura arqueológica poblada cada vez más por pastores menos "civilizados" procedentes del norte. Un área está en cuarto creciente y otra en cuarto menguante. Los desarrollos y declives en un área son distintos respecto a los que se producen en otras, pero muestran complementariedades que no son fortuitas, sino que están interrelacionadas de manera sistemática. Un patrón detectable es que los centros de desarrollo evolutivo cultural no son estáticos, sino que cambian o se reemplazan uno al otro en el transcurso del tiempo. La "acción" evolutiva cultural tiene lugar en diferentes áreas, en diversos momentos a través de las estepas y de la frontera septentrional del Próximo Oriente Antiguo. En el Neolítico, los desarrollos culturales son muy espectaculares en Anatolia; en el Calcolítico, suceden en los Balcanes abarcando, a través de Rumania, Moldavia y Ucrania occidental; más tarde el Cáucaso, Asia Central meridional e Iran oriental, a través de los Urales, etc. A este respecto, la Prehistoria final aparentemente se asemeja a la era histórica moderna con sus cambios consecutivos en el poder mundial. Las hegemonías políticas y económicas nunca son permanentes sino que ascienden y decaen principalmente como resultado de procesos macro-históricos siempre cambiantes e interconectados, y tales procesos macro-históricos son imposibles de detectar arqueológicamente si uno se centra en los desarrollos en una sola región o sobre un horizonte cronológico relativamente restringido de unos centenares de años.

La tarea básica del arqueólogo como historiador de la cultura no es recopilar y ordenar nuevos datos y refinar sin cesar las secuencias cronológicas locales; el historiador de la cultura tiene que aprovechar también la única fortaleza real del registro arqueológico: su macro-perspectiva temporal y espacial de grano grueso concerniente a las actividades productivas básicas realizadas por los diferentes grupos, para intentar discernir entonces cómo estas actividades distintas se relacionan unas con otras o están interconectadas. Las culturas se imbrican continuamente y quedan atrapadas en procesos históricos compartidos que exceden las áreas que ocupan, y la evolución cultural no pasa normalmente por desarrollos internos y adaptaciones locales a escenarios ambientales restringidos, sino que ocurre como producto de esas interconexiones y experiencias compartidas. Tales procesos a gran escala, que implican el desarrollo de nuevas tecnologías y economías y movimientos a gran escala de los materiales a través de distintas formas de intercambio y de migraciones de las gentes, estuvieron actuando en las estepas de Eurasia durante la Edad del Bronce afectaron profundamente a las incontables culturas arqueológicas que han sido definidas por toda este amplia área y por las tierras adyacentes más al sur.

La evolución cultural es real en el sentido de que los cambios tecnológicos acumulativos y los sociales cualitativos tuvieron lugar en el transcurso del tiempo y pueden ser trazados. Las culturas evolucionan de forma evidente de manera que, a largo plazo, muestran un cambio tecnológico progresivo y un mayor control sobre las fuerzas de la naturaleza, resultando en desarrollos cualitativamente nuevos en la organización económica y social. Tales procesos suceden no sólo dentro de culturas individuales, sino que caracterizan también a la cultura humana como una evolución general, total, y como una evolución cultural específica a la vez (Sahlins y Service 1960). Evolución e historia no son conceptos opuestos si no, más bien, complementarios. La evolución general, tal como fue originalmente definida por 
Marshall Sahlins y Elman Service (1960), por tanto, es una historia "mundial" en el sentido de que la evolución tiene lugar a una escala interconectada en la que diferentes gentes participan de manera distinta (cf. Yoffee 2005: 197). La Mesopotamia de la "revolución urbana" y los ascensos y recaídas periódicas de los variados estados que redefinieron continuamente la civilización mesopotámica durante tres milenios, no pueden verse de forma aislada; más bien, la aparición y desarrollo inicial de Mesopotamia tiene que situarse dentro de unos "ámbitos sociales" superpuestos, que se extienden, al menos, desde los Balcanes y las tierras que bordean el Mediterráneo oriental en el oeste, a las estepas euroasiáticas al norte hasta el Asia Central y los centros urbanos del valle del Indo al este. Por todos estos ámbitos interconectados los desarrollos en un área estuvieron asociados con desarrollos y declives en otras áreas.

Los procesos evolutivos locales y los difusionistas más amplios se complementan unos a otros. Históricamente, se abusó de ambas perspectivas y se solían ensalzar las virtudes de la supuesta superioridad de los pueblos, pero ninguno de esos puntos de vista era inherentemente racista $\mathrm{y}$, por supuesto, ambos pueden invocarse para resaltar nuestra humanidad común. La difusión mediante ámbitos sociales superpuestos no requiere un área nuclear, ni una raza dominadora responsable de las innovaciones que son tardíamente adoptadas por gentes menos creativas. Una perspectiva difusionista realista traza la propagación de las innovaciones en múltiples direcciones; la Ruta de la Seda para el oeste es la Ruta del Caballo para China. El concepto de ámbitos sociales compartidos, superpuestos e interconectados destaca, si se quiere, el carácter multilinear de los procesos difusionistas. Lo mismo que el concepto de evolución multilinear o de trayectorias diversas del desarrollo evolutivo, defendido inicialmente por Steward (1955), la difusión se produce a lo largo de múltiples vías o trayectorias y no debe ser secuestrada para documentar un cambio que emana de un foco o patria excepcionalmente innovadora y sigue hacia fuera en una dirección única previamente ordenada.

Esas gentes, que estuvieron implicadas en diferentes actividades, pastoreo, cultivo, minería y comercio, se hicieron tanto a sí mismas como a la Edad del Bronce de Eurasia, pero lo hicieron interactuando unas con otras, reuniendo su conocimiento y experiencias, intercambiando materiales y desplazándose de forma continua y periódica de un área a otra. Los procesos de interconexión que se desarrollaron en la Edad del Bronce han continuado acelerándose y expandiéndose en el transcurso del tiempo hasta llegar a nuestra era, cualitativamente distinta, de globalización. Tanto entonces como ahora las gentes se implicaron constantemente en el intercambio de objetos materiales, ideas e invenciones, aprendiendo unas de otras.

V. Gordon Childe (1944) usó la metáfora de corrientes separadas atrayendo las aguas de sus afluentes para unirse, en último término, en un gran río único para explicar, según sus palabras, Qué sucedió en la Historia. Los biólogos nos dicen que la evolución convergente sucede cuando dos especies relacionadas distantes desarrollan de manera independiente rasgos físicos similares y llegan a parecerse muy estrechamente la una a la otra debido a su adaptación a nichos ecológicos similares. Como es usual, la evolución biológica y la cultural funcionan de manera diferente. La convergencia evolutiva cultural se refiere a los procesos históricos en curso que comenzaron durante el Paleolítico en los cuales ámbitos sociales abiertos llegan a incorporarse a ámbitos sociales cada vez más amplios hasta que alcanzamos la era actual de la globalización.

Corrientes separadas fluyen hacia sus afluentes que se transforman en ríos poderosos, todos los cuales se funden en último término en un único océano que abarca el planeta. Los arqueólogos tienen el privilegio de documentar la mayoría de la historia que define esta evolución general.

Para concluir, considerar que en septiembre de 1944 cuando la Segunda Guerra Mundial concluyó espasmódica y sangrientamente, se celebró una conferencia internacional en la Universidad de Londres para evaluar el futuro de la arqueología europea y para argumentar enérgicamente que su práctica debía trascender las fronteras nacionales; los errores del pasado, tales como escribir prehistorias individuales para naciones-estado separadas, debían ser superados. La Prehistoria tenía que ser una empresa internacional o, si se quiere, universal. Childe hizo el discurso inaugural de esta conferencia. Escribió:

"La Arqueología -sensu stricto- trata, felizmente, con objetos físicos concretos... no puede haber desacuerdo con respecto a ellos. Ahí están para que el estudiante los estudie y observe... Este 
hecho real les capacita para ser la base para un estudio cooperativo internacional de un modo como las características de la historia política, militar o eclesiástica nunca podrían serla... El carácter concreto, sustancial y objetivo [de la Arqueología] la hace una ciencia social... un aspecto de la actividad humana que es el mismo para toda la humanidad, una base verdaderamente universal y, por lo tanto, propiamente el fundamento para una cooperación internacional amistosa (Childe 1944: 6-7).

Hoy esas afirmaciones tan esperanzadas parece un poco color de rosa o ingenuas; se han llevado a la práctica sólo de modo parcial. Los arqueólogos europeos están intentando todavía definir una arqueología para Europa, en mucha menor medida para el mundo en su conjunto. El intento inicial de Grahame Clark en 1961 de esbozar una Prehistoria mundial para que sus lectores pudieran contextualizar las historias de sus propias culturas en términos de desarrollos globales fue abandonada en ediciones posteriores de su libro en las que relacionaba secuencias evolutivas separadas, adoptando, en otras palabras, una perspectiva de cultura en adaptación a condiciones locales. Esta perspectiva es la que caracteriza hoy los textos más populares e, incluso, los resúmenes más serios de la Prehistoria mundial. El énfasis no está en las interconexiones sino en cómo todos nosotros, eventualmente, recorremos las mismas vías de desarrollo yendo unos, simplemente, más lejos que otros.

El espíritu de esa conferencia de 1944 debe ser revivido. La necesidad de una cooperación internacional es todavía real y, de hecho, la Arqueología hoy es cada vez más una empresa de colaboración internacional; los días imperiales cuando se realizaban excavaciones arqueológicas en el exterior con escasa o ninguna participación de colegas y autoridades gubernamentales locales han quedado muy atrás. Las tecnologías para desarrollar investigaciones arqueológicas acordes con el estado de la cuestión son, como las tecnologías de la Edad del Bronce, eminentemente transferibles. Los arqueólogos locales en todos los países en los que he trabajado o que he visitado recientemente, emplean sus cámaras digitales, sistemas SPG y SIG, y distintas técnicas de teledetección espacial y técnicas radiométricas de datación. Los vacíos tecnológicos se han cerrado rápidamente, aunque la ayuda financiera a menudo todavía es apreciada.
En el lado negativo, las historias e interpretaciones nacionalistas del remoto pasado todavía siguen siendo inventadas conscientemente y los participantes en numerosos conflictos étnicos por todo el globo continúan usándolas para suscribir sus cuestionables agendas políticas. Subsiste, en resumen, la necesidad de una perspectiva antropológica en Prehistoria que enfatice su naturaleza compartida, que es una historia a la que todas las gentes han contribuido y de la que todos se han beneficiado gracias a sus interacciones continuas con los demás. Lo que nos une como seres humanos es mucho más que los que nos separa culturalmente. Los evolucionistas han demostrado que, en cuanto a la conducta, hemos respondido de forma similar y hemos seguido trayectorias cualitativamente comparables de desarrollo social, manifestando una "unidad psíquica" común. Estamos, sin embargo, unidos también por el hecho de que los grupos humanos se han desarrollado siempre en contacto con otros grupos, beneficiándose continuamente de esta fertilización cruzada. La evolución cultural tiene lugar en ámbitos sociales compartidos y el reconocimiento de este hecho debe ayudarnos a trascender los prejuicios y los temas que todavía demasiado a menudo nos dividen.

\section{AGRADECIMIENTOS}

Este artículo fue presentado como Lección magistral de la División Arqueológica en las reuniones de la American Anthropological Association en Washington, DC el 30 de noviembre de 2007. Al autor le gustaría expresar su sincera gratitud al Comité de la División de Arqueología que le seleccionó para esta presentación. Reconoce también la ayuda de Stephan Burmeister y Petar Zidarov que le facilitaron información e imágenes sobre los primeros vehículos con ruedas y sobre los depósitos de Troya y Borodino, respectivamente. Finalmente, le gustaría agradecer también los comentarios críticos y sugerencias de Tom Boellstorff, Nick Kardulias y dos anónimos evaluadores del American Anthropologist (6).

(6) La revista TP agradece a Antonio Uriarte González (Laboratorio de Arqueología del Paisaje y Teledetección, CCHS-CSIC, Albasanz 26-28; 28037 Madrid) su adaptación de la lámina II. 


\section{BIBLIOGRAFÍA}

Anthony, D.W. 2007: The Horse, the Wheel, and Language: How Bronze-Age Riders from the Eurasian Steppes Shaped the Modern World. Princeton University Press. Princeton.

Bakker, J.A.; Kruk, J.; Lanting, A.E. y Milisauskas, S. 1999: "The earliest evidence of wheeled vehicles in Europe and the Near East". Antiquity 73 (282): 778-790.

Beck, R.A. Jr.; Bolender, D.; Brown, J.A. y Earle, T.K. 2007: "Eventful Archaeology: the Place of Space in Structural Transformation". Current Anthropology 48: 807-832.

Binford, L.R. 1972: "Some Comments on Historical Versus Processual Archaeology”. En L.R. Binford. An Archaeological Perspective. Seminar Press. New York: 114-121.

Burmeister, S. 2004: "Der Wagen im Neolithikum und in der Bronzezeit: Erfindung, Ausbreitung und Funktion der ersten Fahrzeuge". En M. Fansa y S. Burmeister (eds.): Rad und Wagen. Der Ursprung einer Innovation: Wagen im Vorderen Orient und Europa. Beiheft der Archaologische Mitteilungen aus Nordwestdeutschland 40. Verlagg Philipp von Zabern. Mainz am Rhein: 13-40.

Chernykh, E.N. 1992: Ancient Metallurgy in the USSR: the Early Metal Age. Cambridge University Press. Cambridge.

Chernykh, E.N. 1997: Kargaly: Zabytyi Mir. "NOX" Publishing House. Moscow.

Chase-Dunn, C. y Hall, T.D. 1995: "Cross-World System Comparisons: Similarities and Differences". En S.K. Sanderson (ed.): Civilizations and World Systems: Studying World Historical Change. AltaMira. Walnut Creek, California: 109-135.

Chase-Dunn, C. y Hall, T.D. 1997: Rise and Demise: Comparing World-Systems. Westview. Boulder, Colorado.

Childe, V.G. 1944: "Introduction to the Conference". En Conference on the Problems and Prospects of European Archaeology. Occasional Paper 6, University of London, Institute of Archaeology. London: 6-13.

Earle, T. 1984: "Introduction". En T. Earle (ed.): On the Evolution of Complex Societies: Essays in Honor of Harry Hoijer 1982. Undena Press. Malibu, California: 1-6.

Evans, R.J. 1999: In Defense of History. W.W. Norton. New York.

Flannery, K.V. 1982: "The Golden Marshalltown: A Parable for the Archeology of the 1980s". American Anthropologist 84 (2): 265-278.

Flannery, K.V. 2006: "On the Resilience of Anthropological Archaeology”. Annual Review of Anthropology 35: 1-13.
Gimbutas, M. 1989: The Language of the Goddess. Harper Collins. New York.

Johnson, A. y Earle, T.K. 1987: The Evolution of Human Societies: From Foraging Group to Agrarian State. Stanford University Press. Stanford.

Kepecs, S. y Kohl, P.L. 2003: "Conceptualizing Macroregional Interaction: World-Systems Theory and the Archaeological Record". En M.E. Smith y F.E. Berdan (eds.): The Postclassic Mesoamerican World. The University of Utah Press. Salt Lake City: 14-20.

Kohl, P.L. 1989: "The Use and Abuse of 'World Systems Theory' the Case of the 'Pristine' West Asian State". En C.C. Lamberg-Karlovsky (ed.): Archaeological Thought in America. Cambridge University Press. Cambridge: 218-240.

Kohl, P.L. 2005: "Invariant Homo Politicus and the Biological Constraints on Cultural Evolution". $\mathrm{Cu}$ rrent Anthropology 46: 685-687.

Kohl, P.L. 2007: The Making of Bronze Age Eurasia. Cambridge University Press. Cambridge.

Kohl, P.L. y Chernykh, E.N. 2003: "Different Hemispheres, Different Worlds". En M.E. Smith y F.E. Berdan (eds.): The Postclassic Mesoamerican World. The University of Utah Press. Salt Lake City: 307-312.

Kroeber, A.L. 1935: "History and Science in Anthropology". American Anthropologist 37 (4): 539-569.

Lesser, A. 1985a: "Anthropology and the Future of Internationalism”. En S.W. Mintz (ed.). History, Evolution, and the Concept of Culture: Selected Papers by Alexander Lesser. Cambridge University Press. Cambridge: 140-149. 1. ${ }^{a}$ ed. Lesser 1974.

Lesser, A. 1985b: "Social Fields and the Evolution of Society". En S.W. Mintz (ed.): History, Evolution, and the Concept of Culture: Selected Papers by Alexander Lesser. Cambridge University Press. Cambridge: 92-99. 1. ${ }^{\mathrm{a}}$ ed. Lesser 1961.

McConchie, M. 2004: Archaeology at the North-east Anatolian Frontier, V: Iron Technology and IronMaking Communities of the First Millennium B.C. Peeters. Louvain.

Parkinson, W.A. y Galaty, M.L. 2007: "Secondary States in Perspective: An Integrated Approach to State Formation in the Prehistoric Aegean". American Anthropologist 109, 1: 113-129.

Primas, M. 2007: "Innovationstransfer vor 5000 Jahren: Knotenpunkte am Land- und Wasserwegen zwischen Vorderasien und Europa. Erste Thomsen-Vorlesung Berlin 2006". Eurasia Antiqua 13: $1-19$.

Ratnagar, S. 2001: "The Bronze Age: Unique Instance of a Preindustrial World System?". Current Anthropology 42: 351-379.

Sahlins, M. y Service, E. (eds.) 1960: Evolution and Culture. University of Michigan Press. Ann Arbor. 
Stein, G.J. 1999: Rethinking World-Systems: Diasporas, Colonies, and Interaction in Uruk Mesopotamia. University of Arizona Press. Tucson.

Steward, J. 1949: "Cultural Causality and Law: A Trial Formulation of the Development of Early Civilizations". American Anthropologist 51: 1-27.

Steward, J. 1955: Theory of Culture Change. University of Illinois Press. Urbana-Champaign.

Tolstikov, V. y Treister, M. 1996: The Gold of Troy: Searching for Homer's Fabled City. Harry N. Abrams. New York (asociada con el Pushkin State Museum of Fine Arts and the Ministry of Culture of the Russian Federation, Moscow).

Trigger, B.G. 1991: "Constraint and Freedom: A New Synthesis for Archeological Explanation”. American Anthropologist 93 (3): 551-569.

Wallerstein, I. 1974: The Modern World-System I: Capitalist Agriculture and the Origins of the European World-Economy in the Sixteenth Century
(Studies in Social Discontinuity). Academic Press. New York.

Windschuttle, K. 1996: The Killing of History. Free Press. New York.

Wolf, E.R. 1982: Europe and the People Without History. University of California Press. Berkeley.

Wolf, E.R. 1984: "Culture: Panacea or Problem?". American Antiquity 49 (2): 393-400.

Yoffee, N. 2005: Myths of the Archaic State: Evolution of the Earliest Cities, States, and Civilizations. Cambridge University Press. Cambridge.

Zidarov, P.N. 2005: "Problemy ustanovleniya mestorozhdenii nefrita, zhadeita i lazurita, ispol'zovannykh dlya izgotovleniya toporov-skipetrov, naidennyykh v Troe". En Archaeomineralogy and Early History of Mineralogy, International Seminar Materials. Institute of Geology, Komi Scientific Center, Urals Division, Russian Academy of Sciences. Sytykvar, Komi Republic, Russia: 124-126.

www.Luarna.com anuncia la edición digital (eBook y PC), para el público general de lengua española, de una obra de divulgación sobre el arte rupestre prehistórico, que presenta los últimos debates científicos sobre varios conjuntos de arte rupestre de cuatro continentes.

www.Luarna.com announces the digital publication (eBook y PC) of a general compilation, in Spanish, on several prehistoric rock art corpora. This work is intended for a broad public, bringing to the scene the latest scientific discussions in this area.

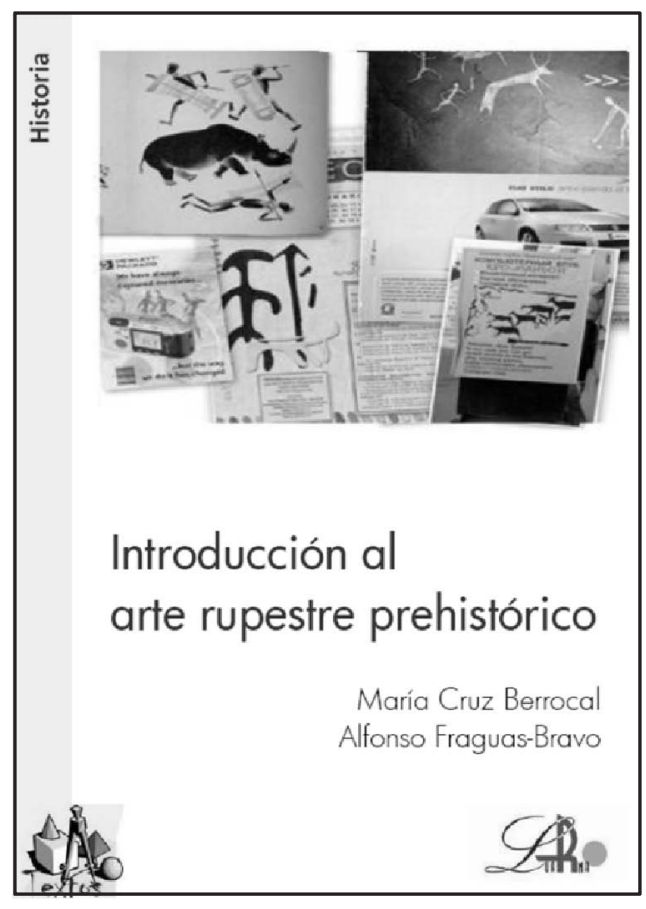

